Supporting Information

\title{
A Highly Stretchable and Conductive Self-Healing Hydrogel for Temperature and Strain Sensing and Chronic Wound Treatment
}

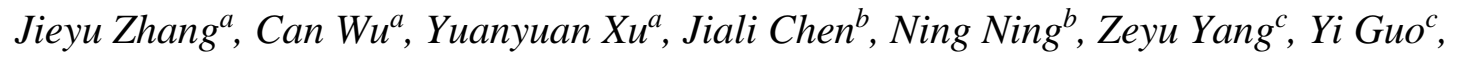
Xuefeng $H u^{a *}$, Yunbing Wang ${ }^{a *}$

${ }^{a}$ National Engineering Research Center for Biomaterials, Sichuan University, Chengdu, Sichuan, 610065, China

${ }^{b}$ Department of Orthopaedics, West China Hospital of Sichuan University, Chengdu, Sichuan, 610041, China

${ }^{\mathrm{c}}$ Rotex Co., Ltd, D6-1104, Tianfu Software Park, High-Tech Zone, Chengdu, Sichuan, 610064, China

* To whom correspondence should be addressed.

E-mail: huxuefeng@scu.edu.cn; yunbing.wang@scu.edu.cn 


\section{Experimental Section}

\subsection{Characterization}

Chemical structures of the compounds were characterized by NMR and FTIR. ${ }^{1} \mathrm{H}$ NMR spectra of the DCS and CS-PPY were obtained using a Bruker AV II-400 MHz NMR spectrometer with a $20 \%(\mathrm{w} / \mathrm{w})$ deuterium chloride solution as the solvent. FTIR spectra of the $\mathrm{CS}, \mathrm{ZnSO}_{4} \cdot 7 \mathrm{H}_{2} \mathrm{O}, \mathrm{ZnCS}$, DCS, CS-PPY were recorded in the range of $400-4000 \mathrm{~cm}^{-1}$ using an FTIR spectrometer (Nicolet 6700, Thermo). Rheological characteristics of the hydrogels were measured using a rheometer (MCR 302, Anton Paar) under a constant strain of $1 \%$ and the angular velocity increasing from $0.01 \mathrm{rad} / \mathrm{s}$ to $100 \mathrm{rad} / \mathrm{s}$ at $25{ }^{\circ} \mathrm{C}$. A CP25-2 cone-plate sensor (diameter $24.990 \mathrm{~mm}$, cone angle $1.999^{\circ}$ ) was adopted for all tests. The stress-strain analyses of the hydrogels were performed on a tensile test machine (EZ-LX, Shimadzu) at a cross-head speed of $10 \mathrm{~mm} / \mathrm{min}$ at $25{ }^{\circ} \mathrm{C}$ using the hydrogel specimen in a dumbbell-shape (the size of tensile part: $15 \mathrm{~mm} \times 2 \mathrm{~mm} \times 2 \mathrm{~mm}$ ). The tests were stopped at specimen break or when the maximum stroke of $500 \mathrm{~mm}$ was reached. The electrical conductivity of the hydrogel was measured using disk-shaped specimens $(12 \mathrm{~mm} \times 1 \mathrm{~mm})$ on a digital four-point probe system (ST 2253, Jingge). To assess the dehydration of the hydrogel, each sample ( $0.3 \mathrm{~g}$ of the PCPZ hydrogel) was placed in a Petri dish without the lid, and the mass of the samples was monitored at the specified times.

\subsection{Cytotoxicity Assay}

Mouse fibroblasts (L929, American Type Culture Collection (ATCC)) were cultured in the Dulbecco's Modified Eagles Medium (DMEM, Gibco) supplemented with $10 \%$ fetal bovine serum (Sciencell), $100 \mathrm{U} / \mathrm{mL}$ penicillin (Gibco) and $100 \mu \mathrm{g} / \mathrm{mL}$ streptomycin (Gibco) at $37{ }^{\circ} \mathrm{C}$ in a $5 \% \mathrm{CO}_{2}$ atmosphere. The hydrogels were cut into disk-shaped specimens (3.5 $\mathrm{mm} \times 2 \mathrm{~mm}$ ) and then sterilized by autoclave. Each sterile specimen was immersed in $3 \mathrm{~mL}$ of DMEM for $24 \mathrm{~h}$ at $37^{\circ} \mathrm{C}$ to prepare the hydrogel extract solution. Ten thousand fibroblasts were seeded in each well of a 96-well plate and pre-cultured in $200 \mu \mathrm{L}$ of fresh DMEM for 24 
$\mathrm{h}$ to allow the complete adhesion. The culture medium was replaced with the hydrogel extract solution, and the cells were cultured for another $24 \mathrm{~h}$. The cell viability was then investigated by a Cell Counting Kit-8 (CCK-8, 7Sea Biotech) assay. Briefly, the medium was changed with $100 \mu \mathrm{L}$ of DMEM and $10 \mu \mathrm{L}$ of CCK-8 reagent. After another $2 \mathrm{~h}$ of incubation, $100 \mu \mathrm{L}$ of the solution was transferred into each well of a new 96-well plate, and the optical density at $450 \mathrm{~nm}\left(\mathrm{OD}_{450}\right)$ was measured using a microplate reader (PowerWave XS, Biotek). For the direct contact test, cells were cultured in a 24 -well microplate for $24 \mathrm{~h}$, and the disk-shaped PCPZ hydrogel specimens $(8 \mathrm{~mm} \times 2 \mathrm{~mm})$ were placed to contact the cells cultured in the microplate. The cell viability was assessed by the CCK-8 asssay after $24 \mathrm{~h}$ of culture.

\subsection{MIC and MBC Measurement}

The MIC and MBC of ZnCS for Staphylococcus aureus (ATCC 25923) and Pseudomonas aeruginosa (ATCC 27853) were tested by the broth microdilution method according to the recommendation of the Clinical Laboratory Standards Institute. Briefly, 10 $\mathrm{mL}$ of tryptic soy broth (TSB) was inoculated with bacteria and then incubated overnight at $37{ }^{\circ} \mathrm{C}$ under shaking. The obtained bacterial suspension was spread on a growth agar plate followed by incubation for $24 \mathrm{~h}$. The isolated colonies were dispersed in PBS and diluted to the desired concentration $\left(\mathrm{OD}_{600}=0.1\right.$ is equivalent to $1 \times 10^{7}$ colony-forming units $(\mathrm{CFU}) / \mathrm{ml}$ (Staphylococcus aureus) or $1 \times 10^{8} \mathrm{CFU} / \mathrm{mL}$ (Pseudomonas aeruginosa)). The bacteria were further diluted with Mueller Hinton broth (MHB) to obtain the inocula at the concentration of $1 \times 10^{6} \mathrm{CFU} / \mathrm{mL}$. After that, each well of a 96-well microplate containing $100 \mu \mathrm{L}$ of $\mathrm{ZnCS}$ suspension (in MHB) at a series of concentrations $(0.25-32 \mathrm{mg} / \mathrm{mL})$ was inoculated with 100 $\mu \mathrm{L}$ of the bacterial suspension followed by incubation at $37{ }^{\circ} \mathrm{C}$ for $24 \mathrm{~h}$. The lowest concentration that inhibits visible growth of bacteria in the broth is MIC, and the minimum concentration that kills $99.9 \%$ of the bacterial cells in the inoculum is the MBC. 
Table S1 Composition of different hydrogels.

\begin{tabular}{|c|c|c|c|c|c|c|}
\hline Sample & $\begin{array}{l}\text { 15\% PVA solution } \\
\text { (g) }\end{array}$ & Borax (g) & $\mathrm{CS}(\mathrm{g})$ & CS-PPY (g) & $\mathrm{ZnCS}(\mathrm{g})$ & Gel property \\
\hline 1 & 10 & 1 & I & 1 & 1 & No gelation \\
\hline 2 & 10 & I & 0.1 & I & l & No gelation \\
\hline 3 & 10 & I & 0.2 & I & I & No gelation \\
\hline 4 & 10 & I & 0.4 & I & I & No gelation \\
\hline 5 & 10 & 0.0375 & I & I & I & PVA/B1 \\
\hline 6 & 10 & 0.075 & I & I & I & PVA/B2 \\
\hline 7 & 10 & 0.15 & I & I & I & PVA/B4 \\
\hline 8 & 10 & 0.0375 & 0.1 & / & I & PVA/B1/CS1 \\
\hline 9 & 10 & 0.0375 & 0.2 & I & l & $\mathrm{PVA} / \mathrm{B} 1 / \mathrm{CS} 2$ \\
\hline 10 & 10 & 0.0375 & 0.4 & I & I & PVA/B1/CS4 \\
\hline 11 & 10 & 0.075 & 0.1 & I & I & $\mathrm{PVA} / \mathrm{B} 2 / \mathrm{CS} 1$ \\
\hline 12 & 10 & 0.075 & 0.2 & I & I & PVA/B2/CS2 (PC) \\
\hline 13 & 10 & 0.075 & 0.4 & I & I & $\mathrm{PVA} / \mathrm{B} 2 / \mathrm{CS} 4$ \\
\hline 14 & 10 & 0.15 & 0.1 & I & I & PVA/B4/CS1 \\
\hline 15 & 10 & 0.15 & 0.2 & I & I & $\mathrm{PVA} / \mathrm{B} 4 / \mathrm{CS} 2$ \\
\hline 16 & 10 & 0.15 & 0.4 & I & I & PVA/B4/CS4 \\
\hline 17 & 10 & 0.075 & 0.2 & 0.05 & I & $\mathrm{PVA} / \mathrm{B} 2 / \mathrm{CS} 2 / \mathrm{CS}-\mathrm{PPY} 0.5$ \\
\hline 18 & 10 & 0.075 & 0.2 & 0.1 & I & PVA/B2/CS2/CS-PPY1 (PCP) \\
\hline 19 & 10 & 0.075 & 0.2 & 0.2 & I & PVA/B2/CS2/CS-PPY2 \\
\hline 20 & 10 & 0.075 & 0.2 & 0.3 & I & $\mathrm{PVA} / \mathrm{B} 2 / \mathrm{CS} 2 / \mathrm{CS}-\mathrm{PPY} 3$ \\
\hline 21 & 10 & 0.075 & 0.2 & 0.1 & 0.025 & PVA/B2/CS2/CSPPY1/ZnCS0.25 \\
\hline 22 & 10 & 0.075 & 0.2 & 0.1 & 0.05 & PVA/B2/CS2/CSPPY1/ZnCS0.5 \\
\hline 23 & 10 & 0.075 & 0.2 & 0.1 & 0.1 & PVA/B2/CS2/CS-PPY1/ZnCS1 \\
\hline 24 & 10 & 0.075 & 0.2 & 0.1 & 0.2 & $\begin{array}{c}\mathrm{PVA} / \mathrm{B} 2 / \mathrm{CS} 2 / \mathrm{CS}-\mathrm{PPY} 1 / \mathrm{ZnCS} 2 \\
\text { (PCPZ) }\end{array}$ \\
\hline
\end{tabular}




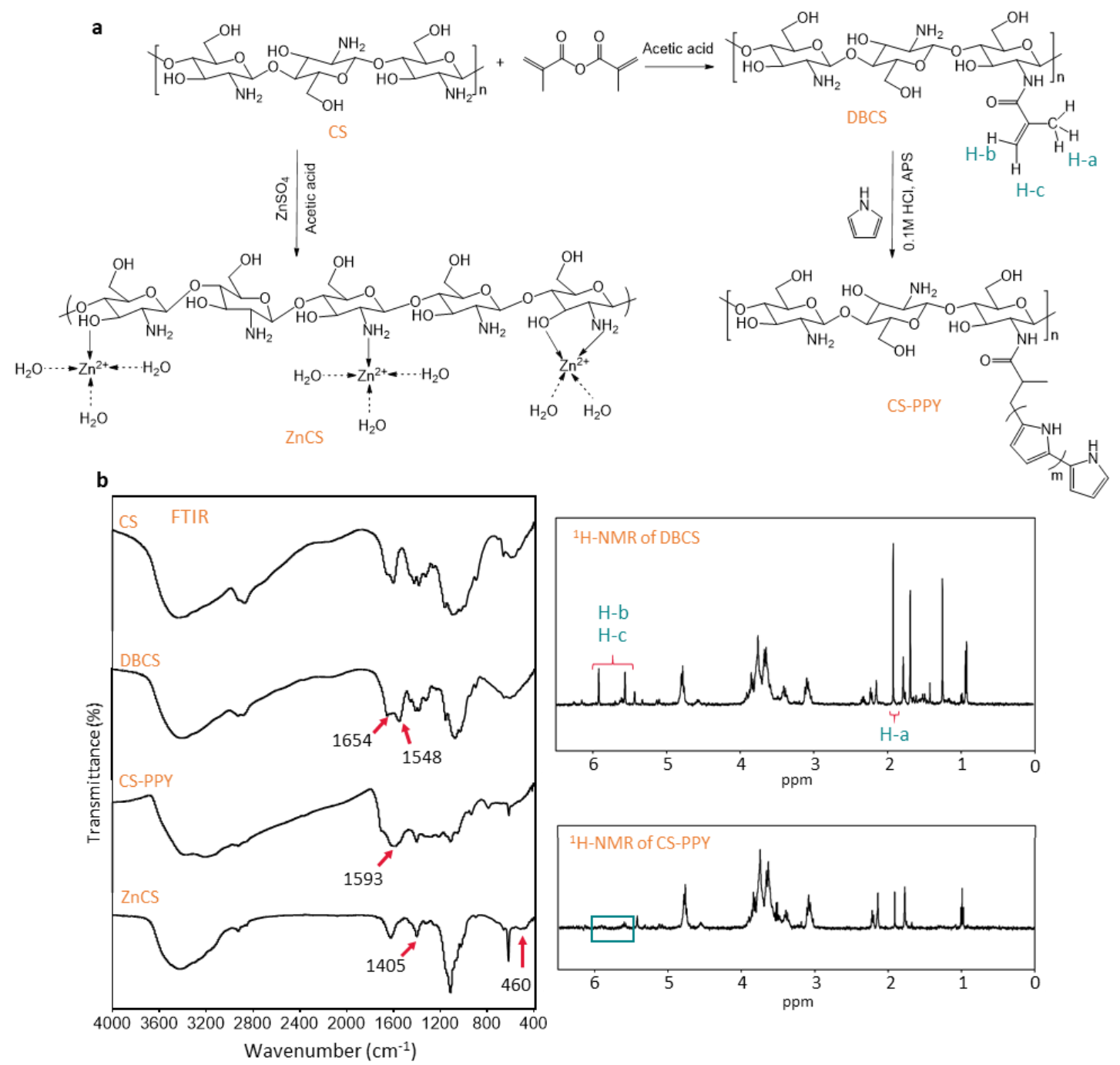

Figure S1 a Schematic illustration of the synthesis of ZnCS and CS-PPY. b FTIR and ${ }^{1} \mathrm{H}$ NMR spectra showing that the DBCS, CS-PPY, ZnCS were successfully synthesized. For the DBCS, the characteristic signals of the grafted moieties $\left(C=O\right.$ amide $\left(1654 \mathrm{~cm}^{-1}\right)$ and $\mathrm{C}=\mathrm{C}$ conjugated $\left(1548 \mathrm{~cm}^{-1}\right)$ bands in the FTIR spectrum and the hydrogen atoms at the $\mathrm{H}-\mathrm{a}(1.92$ ppm), H-b and H-c (5.50-6.00 ppm) positions in the ${ }^{1} \mathrm{H}$ NMR spectrum) were observed. For the CS-PPY, the characteristic signals of the grafted PPY were observed. The presence of the $1593 \mathrm{~cm}^{-1}$ band in the FTIR spectrum is attributed to the C-C in-ring and inter-ring stretching of PPY. The significantly reduced intensity of the peaks of the H-b and $\mathrm{H}-\mathrm{c}$ in the ${ }^{1} \mathrm{H}$ NMR spectrum indicates that the double bonds in the DBCS are consumed. For the $\mathrm{ZnCS}$, the signals assigned to the stretching of O-Zn $\left(460 \mathrm{~cm}^{-1}\right)$ and stretching of C-N $\left(1405 \mathrm{~cm}^{-1}\right)$ in $\mathrm{NH}_{2}-\mathrm{Zn}$ complex appear in the FTIR spectrum. ${ }^{[1]}$ 

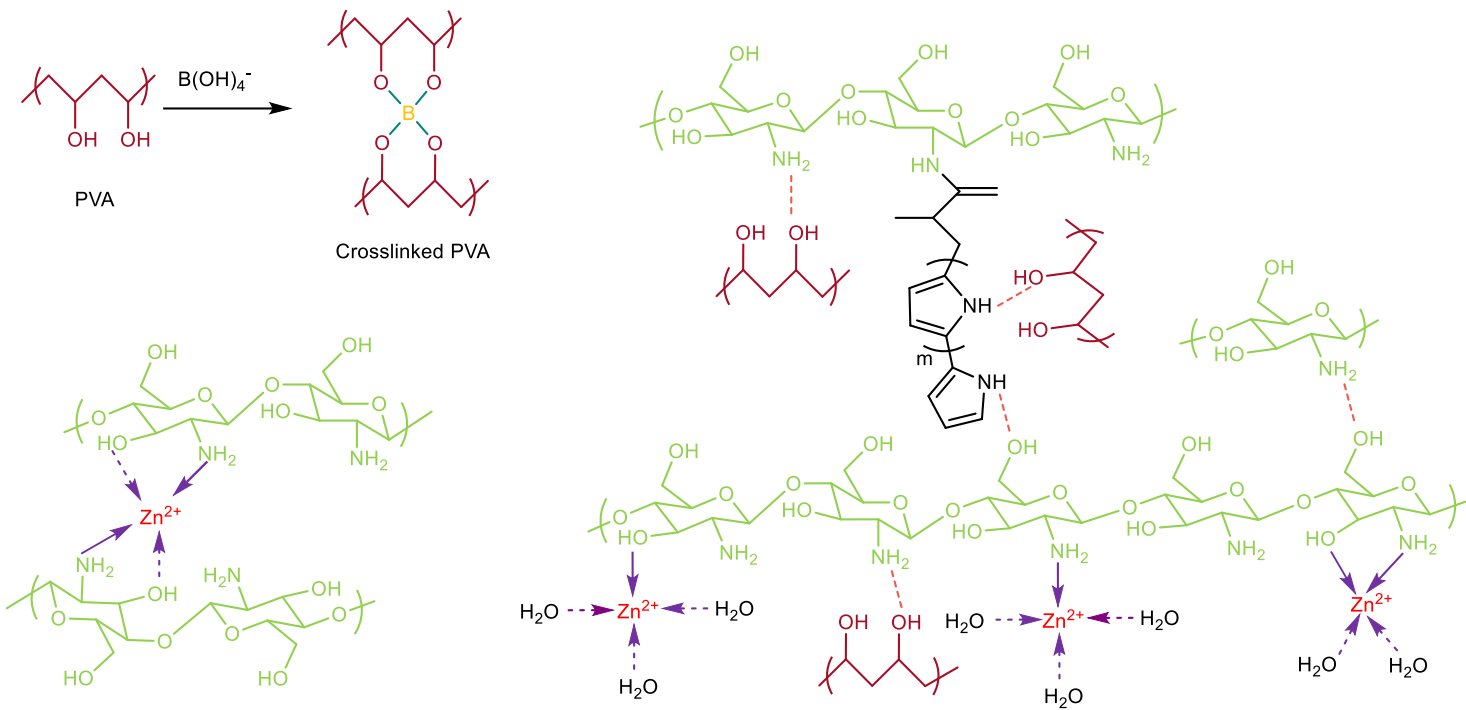

Figure S2 Schematic illustration of multiple crosslinking interactions in the PCPZ hydrogel. 


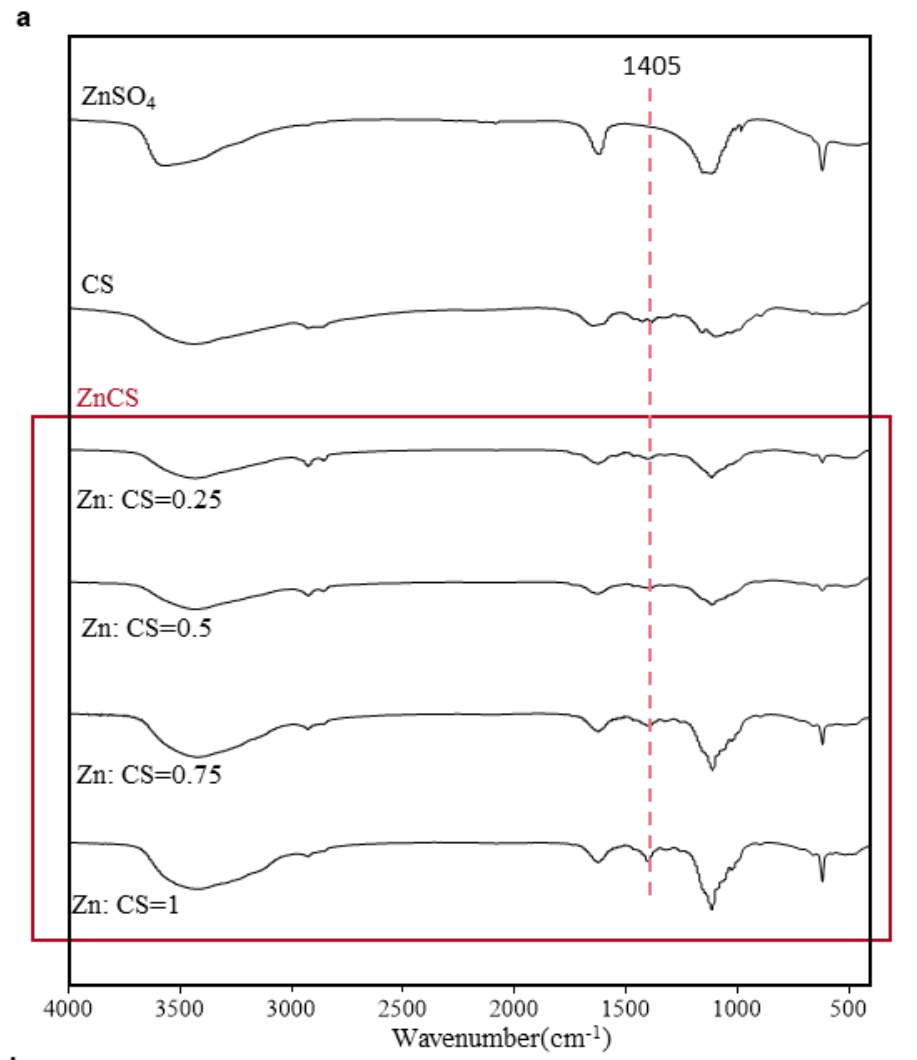

b

\begin{tabular}{|c|c|c|c|c|}
\hline & \multicolumn{2}{|c|}{$\begin{array}{c}\text { Pseudomonas } \\
\text { aeruginosa }\end{array}$} & \multicolumn{2}{|c|}{ Staphylococcus aureus } \\
\hline & $\begin{array}{c}\mathrm{MIC} \\
(\mathrm{mg} / \mathrm{mL})\end{array}$ & $\begin{array}{c}\mathrm{MBC} \\
(\mathrm{mg} / \mathrm{mL})\end{array}$ & $\begin{array}{c}\mathrm{MIC} \\
(\mathrm{mg} / \mathrm{mL})\end{array}$ & $\begin{array}{c}\mathrm{MBC} \\
(\mathrm{mg} / \mathrm{mL})\end{array}$ \\
\hline $\mathrm{Cn}: \mathrm{CS}=0.25$ & $>32$ & $>32$ & $>32$ & $>32$ \\
\hline Zn: $\mathrm{CS}=0.5$ & 8 & 32 & $>32$ & $>32$ \\
\hline $\mathrm{Zn}: \mathrm{CS}=0.75$ & 4 & 16 & 8 & 8 \\
\hline $\mathrm{Zn}: \mathrm{CS}=1$ & 2 & 4 & 2 & 2 \\
\hline
\end{tabular}

Figure S3 a FTIR spectra of $\mathrm{ZnSO}_{4}, \mathrm{CS}$, and $\mathrm{ZnCS}$ fabricated with different $\mathrm{Zn}$ : CS ratios. The band at $1405 \mathrm{~cm}^{-1}$ is assigned to stretching of $\mathrm{C}-\mathrm{N}$ in $-\mathrm{NH}_{2}-\mathrm{Zn}$ complex, and it enhances with increasing $\mathrm{Zn}$ content. b MIC and MBC of CS and $\mathrm{ZnCS}$ against Pseudomonas aeruginosa and Staphylococcus aureus. $\mathrm{n}=3$. 

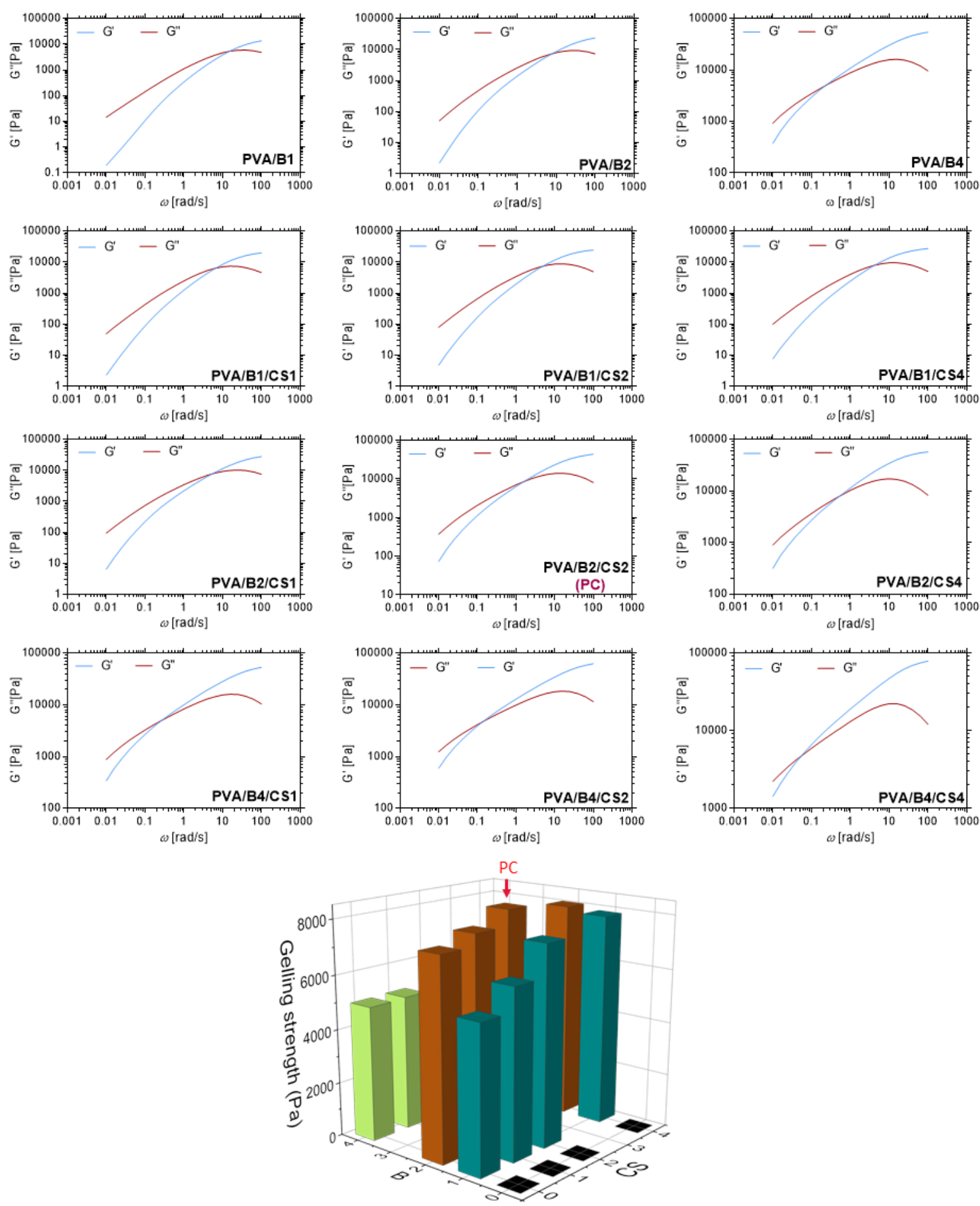

Figure S4 Rheological properties of the matrix hydrogels prepared with different ratios of PVA, borax, and CS. The bottom insert summarizes the effect of borax and CS on the gelling strength, showing that the PC hydrogel had the highest gelling strength. 

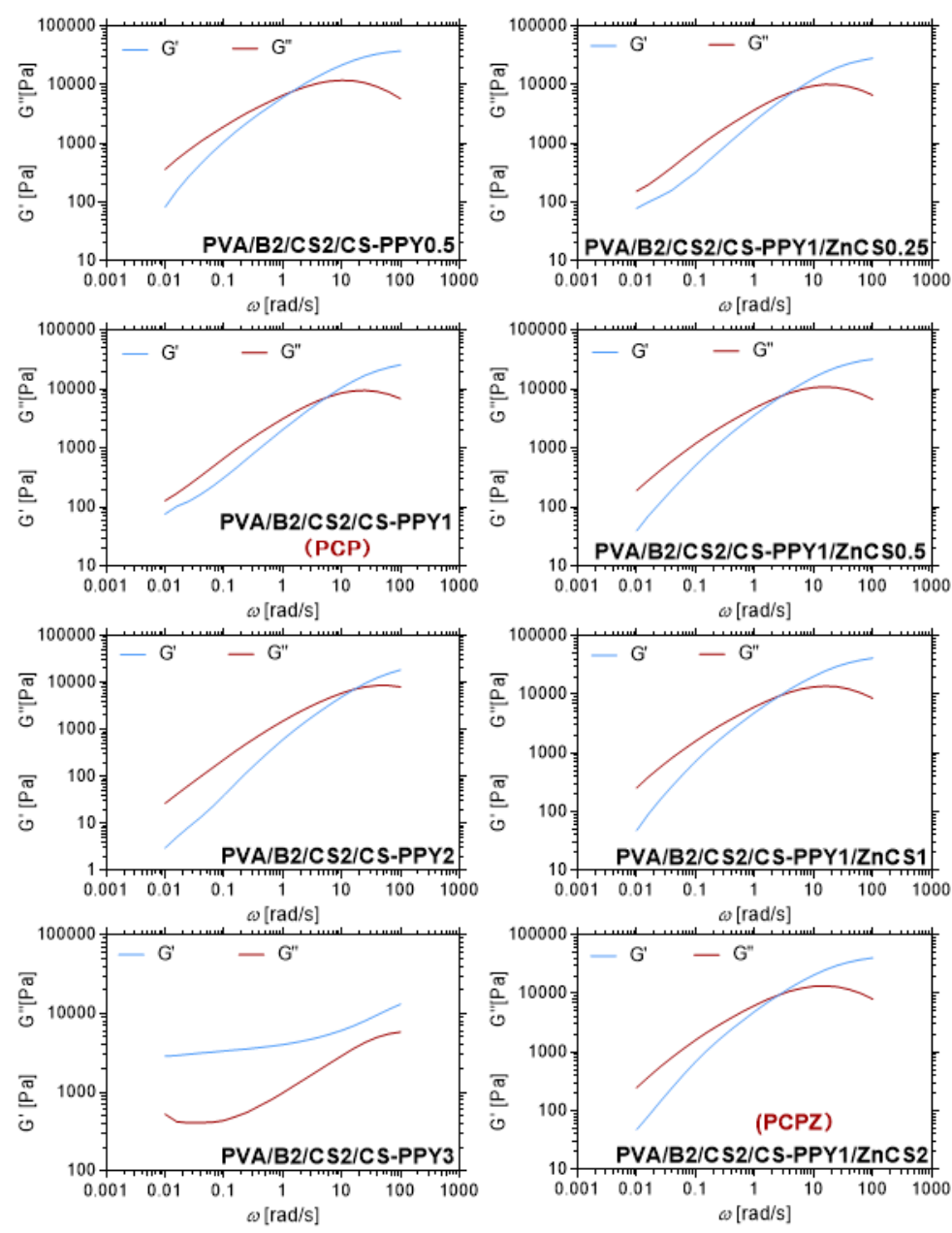

Figure S5 Rheological properties of the PC hydrogels supplemented with different amounts of CS-PPY and ZnCS. 

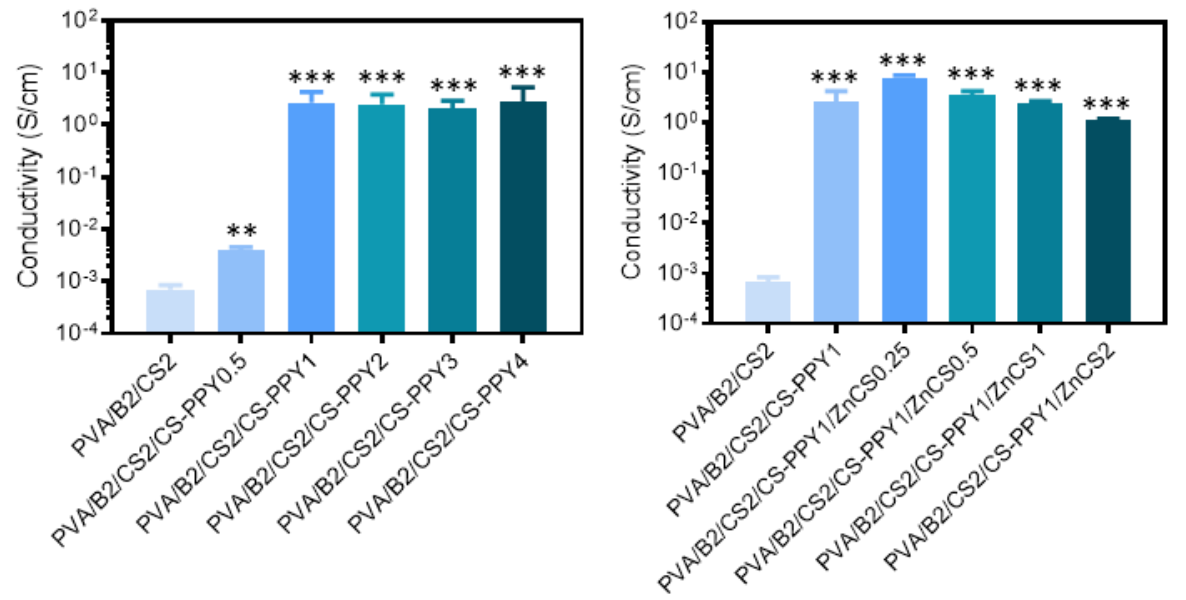

Figure S6 Conductivity of the PC hydrogels supplemented with different amounts of CS-PPY and $\mathrm{ZnCS}$. * indicates significant difference compared with the PVA/B2/CS2 (PC) group. $\mathrm{n}=3$. 


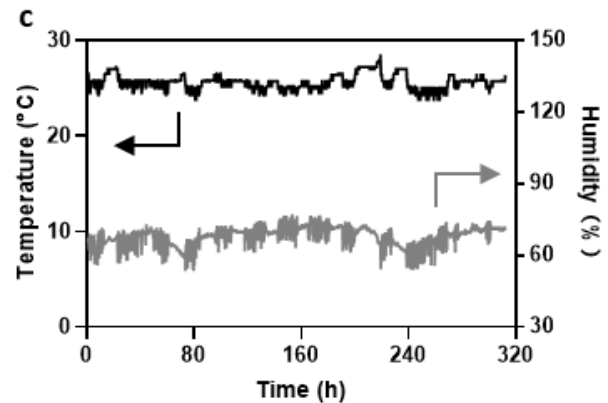

Figure S7 Records of the temperature and humidity of the environment where the dehydration test was conducted. 


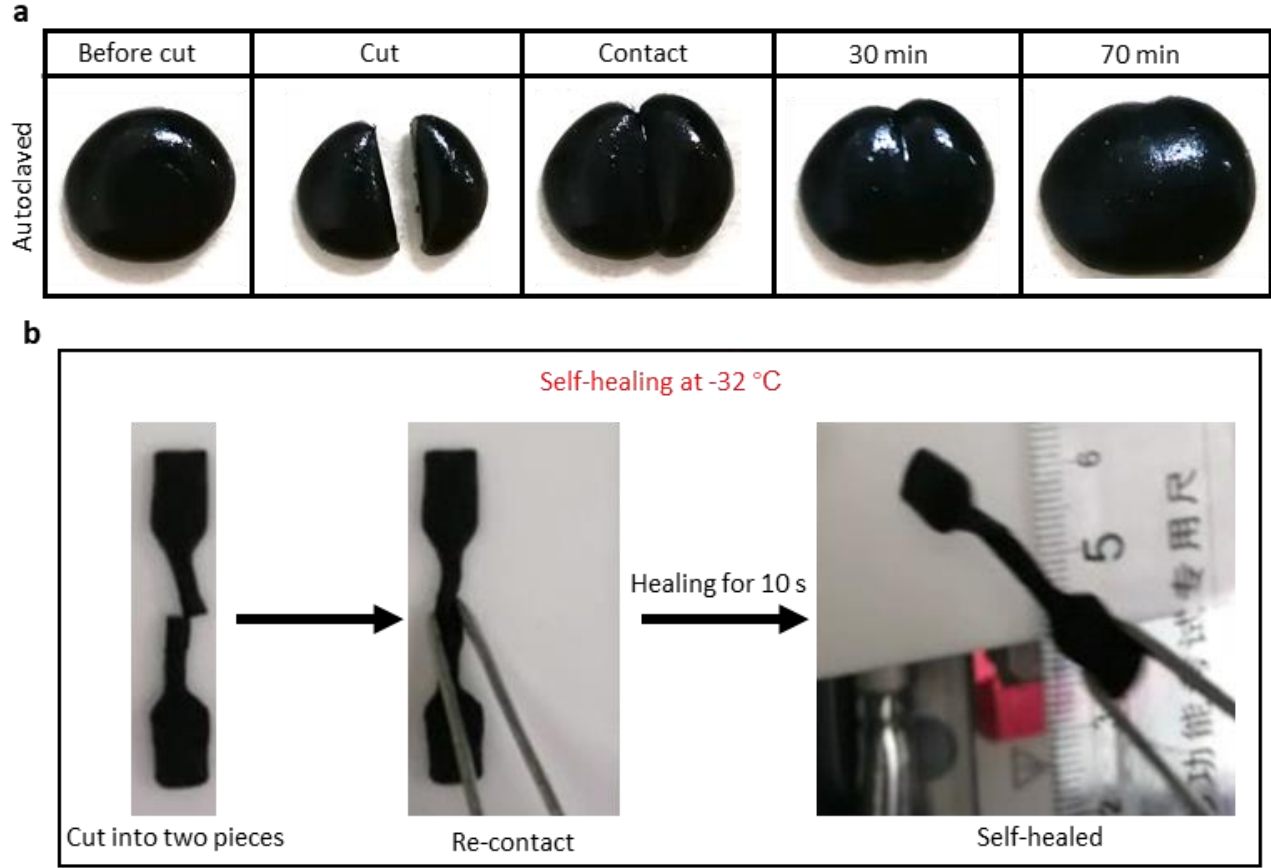

Figure S8 a Photos showing that the PCPZ hydrogel can self-heal after autoclaving. b Photos showing that the PCPZ hydrogel can self-heal at $-32{ }^{\circ} \mathrm{C}$. 

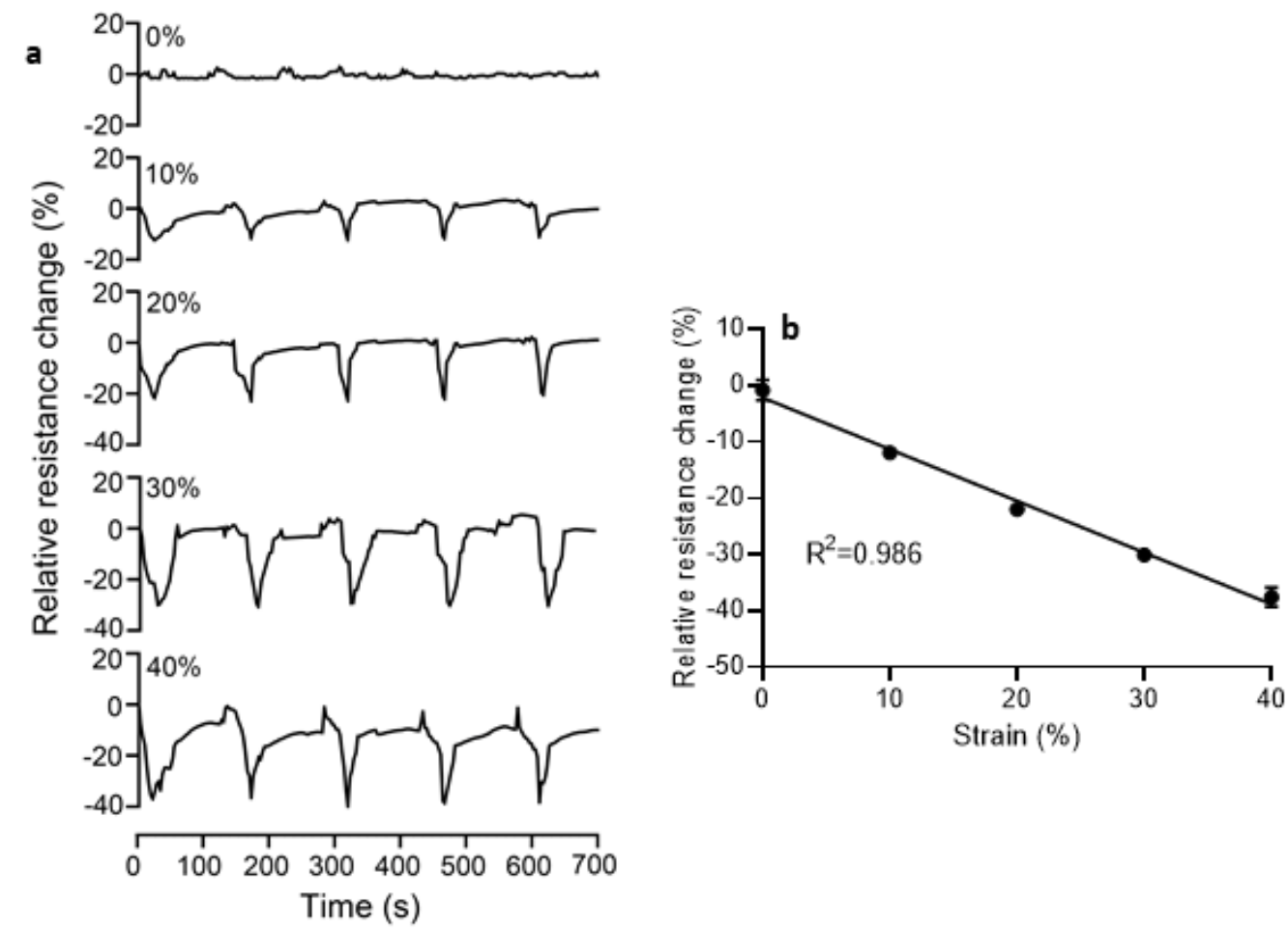

Figure S9 a Record of the relative resistance change of the PCPZ hydrogel when it was cyclically compressed at different strains. b Linear relationship between the relative resistance change and the strain. 


\section{Reference}

(1) Tang, L. G.; Hon, D. N. S. Chelation of Chitosan Derivatives with Zinc Ions. II. Association Complexes of $\mathrm{Zn}^{2+}$ onto $O, N$-Carboxymethyl Chitosan. J. Appl. Polym. Sci. 2001, 79(8), 1476-1485, DOI: 10.1002/1097-4628(20010222)79:8<1476::AID-APP150>3.0.CO;2A. 